\title{
Aerobic exercise training in Kartagener's syndrome: case report
}

\author{
Aslihan Cakmak',**, Deniz Inal-Ince ${ }^{1}$, Hazal Sonbahar-Ulu', Cemile Bozdemir-Ozel', Haluk Tekerlek', Melda Saglam', \\ Ebru Calik-Kutukcu', Naciye Vardar-Yagli', Elmas Ebru Yalcin², Ugur Ozcelik², Hulya Arikan' \\ 'Department of Physical Therapy and Rehabilitation, Hacettepe University, Ankara, Turkey \\ ${ }^{2}$ Department of Pediatric Chest Medicine, Faculty of Medicine, Hacettepe University, Ankara, Turkey
}

Kartagener's syndrome is a rare, autosomal recessive inherited disease, which is characterized by a triad of chronic sinusitis, bronchiectasis, and situs inversus. In this report, we aimed to represent the effect of aerobic exercise training in addition to chest physiotherapy in an outpatient with Kartagener's syndrome. An 18-year-old female diagnosed with Kartagener's syndrome applied with the complaints of productive cough and dyspnea with exertion and attended pulmonary rehabilitation program comprising exercise training in addition to standard treatment. Aerobic exercise training was performed three times weekly at $80 \%$ of the peak heart rate, for 8 weeks as supervised sessions. Respiratory physiotherapy and postural exercises were taught to the patient to be performed at home each day of the week. Before and after pulmonary rehabilitation program, incremental shuttle walk test (ISWT) was performed; dyspnea and fatigue were assessed using Borg Scale. Pulmonary function test was evaluated using spirometer. The patient wore activity monitor for 7 consecutive days before and after training. After pulmonary rehabilitation program, 90-m increase in ISWT was observed. We recommend exercise training in patients with Kartagener's syndrome to increase exercise capacity. Further randomized control trial is needed to clarify the effects.

Keywords: Bronchiectasis, Exercise, Pulmonary rehabilitation, Respiratory disease

\section{INTRODUCTION}

Primary ciliary dyskinesia is a rare autosomal recessive inherited disease with the congenital abnormality of the primary cilia. Situs inversus totalis (complete mirror-image reversal of the thoracic and abdominal organs) is present in $50 \%$ of patients with primary ciliary dyskinesia (Leigh et al., 2009). The triad of situs inversus, bronchiectasis, and chronic sinusitis became known as Kartagener's syndrome. The dysfunction of ciliary motility leading to impaired mucociliary clearance. Accumulated secretions on the epithelial surface and following persistent or recurrent bacterial infections result in bronchiectasis. Respiratory physiotherapy involving the combination of airway clearance techniques and exercise is recommended to alleviate the sputum clearance and may suppress the further deteriorative impacts of diseases. There is no random- ized study in the treatment of primary ciliary dyskinesia/Kartagener's syndrome. As the aim is to correct or maintain the normal lung function for all chronic respiratory diseases, all recommendations are derived from cystic fibrosis guidelines, even though it follows a different pathophysiology (Barbato et al., 2009).

Pulmonary rehabilitation in addition to regular chest physiotherapy was shown to improve exercise tolerance, and health-related quality of life in patients with noncystic fibrosis bronchiectasis and this benefit was sustained at 12 weeks post-end of pulmonary rehabilitation (Mandal et al., 2012). Pifferi et al. (2013) reported that up to date proper therapeutical approach in primary ciliary dyskinesia includes the use of respiratory physiotherapy and regular exercise to favor airways clearance and antibiotics administration to control acute airway infections.

In this report, we aimed to represent a case of Kartagener's syn-
${ }^{*}$ Corresponding author: Aslihan Cakmak (i) https://orcid.org/0000-0002-2474-8000 Department of Physical Therapy and Rehabilitation, Hacettepe University, 06100 Samanpazari, Ankara, Turkey

E-mail: aslihancakmak90@gmail.com, aslihancakmak@hacettepe.edu.tr

Received: March 18, 2019 / Accepted: April 9, 2019
This is an Open Access article distributed under the terms of the Creative Commons Attribution Non-Commercial License (http://creativecommons.org/licenses/by-nc/4.0/) which permits unrestricted non-commercial use, distribution, and reproduction in any medium, provided the original work is properly cited. 
drome with showing the effects of aerobic exercise training in addition to chest physiotherapy in an outpatient with Kartagener's syndrome.

\section{MATERIALS AND METHODS}

\section{Case history}

An 18-year-old female Kartagener's syndrome diagnosed patient presented to our outpatient department with the complaints of chronic productive cough and progressive dyspnea with exertion.

\section{Clinical history and demographic information of the patient}

The patient had a past medical history of chronic sinusitis, bronchiectasis, and situs inversus totalis. She was born to consanguineous parents. She consulted to our department with the complaints of a productive cough with yellow sputum and dyspnea on exertion. She had no history of smoking. She was prescribed an inhaler (salmeterol and fluticasone propionate) to use twice daily by her doctor. The signed informed consent was obtained from the patient for the use of the information obtained in the assessment and the treatment process and for the publication of this case report.

\section{Examination}

Her anthropometric features were: body weight, $48 \mathrm{~kg}$; height, $157 \mathrm{~cm}$, and body mass index, $19.47 \mathrm{~kg} / \mathrm{m}^{2}$. Her vital signs were: heart rate (HR), 96 beats/min; respiratory rate, 20 breaths/min; oxygen saturation $\left(\mathrm{SpO}_{2}\right), 91 \%$; blood pressure $110 / 80 \mathrm{mmHg}$. Auscultation of the chest revealed coarse crackles and diminished breath sounds over bilateral lung fields.

\section{Pulmonary function assessment}

Before incremental shuttle walk test (ISWT), pulmonary function was determined according to standard spirometry guideline (Miller et al., 2005). Forced vital capacity (FVC), forced expiratory volume at $1 \mathrm{sec}\left(\mathrm{FEV}_{1}\right)$ (expressed as \% of predicted) and $\mathrm{FEV}_{1} /$ FVC were obtained.

\section{Functional capacity assessment}

The ISWT is an externally paced maximal exercise test that the walking speed is controlled using auditory signals and increases continuously until the participant can no longer continue (Cox et al., 2014). The distance completed by the patient was recorded throughout the test period. $\mathrm{SpO}_{2}$ and $\mathrm{HR}$ were recorded before and after the test using a portable pulse oximeter (Nonin Palmsat 2550A, Noninedical Inc., Plymouth, MN, USA). Before and after the test, blood pressure was measured. Modified Borg Scale was used to evaluate fatigue and dyspnea perception. The completed distance was expressed in meters and as ISWT\% distance, taking the percentage of normal reference values (Probst et al., 2012).

\section{Physical activity assessment}

Physical activity level was determined objectively using SenseWear Armband (SWA) (SenseWear Armband Model MF-SW, BodyMedia, Pittsburgh, PA, USA). Our patient wore SWA for 7 consecutive days. She was informed to remove the device only when in contact with water, such as shower, swimming, etc., and then rewearing it after these kinds of activities. As described in the manual, the device was fitted by adjusting the band tightness relative to the arm of the patient, ensuring that the sensors were in contact with the arm, on the left arm over the triceps. She was asked to continue their daily life activities. The SWA was used, and its validity was tested in various chronic diseases such as chronic obstructive lung disease, cystic fibrosis, and cardiac patients (Cole et al., 2004; Cox et al., 2014; Hill et al., 2010).

\section{Exercise training program}

Exercise training consisted of a prescribed exercise program and included treadmill walking, with the intensity set to $80 \%$ of the peak HR achieved on the ISWT. Our patient participated aerobic exercise training three days of the week through 8 weeks. Monitorization of vital signs including $\mathrm{SpO}_{2}$ and $\mathrm{HR}$ was ensured pre-, during, and postexercise training. Patient continued her standard treatment consisting of respiratory physiotherapy using oscillatory positive expiratory pressure device, postural exercises, and positions to reduce dyspnea to be performed at home.

\section{RESULTS}

Pulmonary function test parameters before and after exercise Table 1. Pulmonary function test parameters before and after exercise training

\begin{tabular}{lcc}
\hline Pulmonary function parameters & Before & After \\
\hline $\mathrm{FVC}(\%)$ & 66.0 & 61.0 \\
$\mathrm{FEV}_{1}(\%)$ & 51.0 & 48.0 \\
$\mathrm{FEV}_{1} / \mathrm{FVC}$ & 69.3 & 66.0 \\
$\mathrm{PEF}(\%)$ & 85.0 & 82.0 \\
$\mathrm{FEF}_{25-75 \%}(\%)$ & 25.0 & 20.0
\end{tabular}

FVC, forced vital capacity; $\mathrm{FEV}_{1}$, forced expiratory volume at $1 \mathrm{sec}$; PEF, peak expiratory flow; $\mathrm{FEF}_{25 \%-75 \%}$, forced expiratory flow at $25 \%-75 \%$ at vital capacity. 
Table 2. Incremental shuttle walk test parameters before and after exercise training

\begin{tabular}{|c|c|c|c|c|}
\hline \multirow{2}{*}{$\begin{array}{l}\text { Incremental shuttle walk test } \\
\text { parameters }\end{array}$} & \multicolumn{2}{|c|}{ Before training } & \multicolumn{2}{|c|}{ After training } \\
\hline & Pretest & Posttest & Pretest & Posttest \\
\hline $\mathrm{HR}$ (beats/min) & 95 & 185 & 103 & 190 \\
\hline Maximum HR (beats/min) & \multicolumn{2}{|c|}{185} & \multicolumn{2}{|c|}{190} \\
\hline Maximum HR\% (\%) & \multicolumn{2}{|c|}{91.58} & \multicolumn{2}{|c|}{94.05} \\
\hline $\mathrm{SpO}_{2}(\%)$ & 95 & 95 & 96 & 87 \\
\hline Systolic blood pressure (mmHg) & 90 & 170 & 110 & 160 \\
\hline Diastolic blood pressure (mmHg) & 60 & 80 & 80 & 90 \\
\hline Dyspnea (Borg 0-10) & 0 & 10 & 0.5 & 4 \\
\hline Quadriceps fatigue (Borg 0-10) & 0 & 10 & 0.5 & 4 \\
\hline Fatigue (Borg 0-10) & 0 & 10 & 1 & 4 \\
\hline ISWT distance (m) & \multicolumn{2}{|c|}{540} & \multicolumn{2}{|c|}{630} \\
\hline ISWT\% distance (\%) & \multicolumn{2}{|c|}{52.94} & \multicolumn{2}{|c|}{61.76} \\
\hline
\end{tabular}

$\mathrm{HR}$, heart rate; $\mathrm{SpO}_{2}$, oxygen saturation; ISWT, incremental shuttle walk test.

training were shown in Table 1 . The patient had evident airway obstruction according to the results before and after aerobic exercise training. The ISWT parameters were shown in Table 2. The parameters such as $\mathrm{HR}, \mathrm{SpO}_{2}$, blood pressure, and fatigue and dyspnea perception to ISWT before and after the exercise training were demonstrated in Table 2. The ISWT distance increased 90 $\mathrm{m}$ after training compared with the distance before aerobic exercise training. The physical activity assessment parameters were shown in Table 3.

\section{DISCUSSION}

Patients with primary ciliary dyskinesia manifest lower aerobic fitness than healthy subjects and their aerobic fitness correlate with pulmonary function and self-reported complaints of limitations in vigorous physical activity (Madsen et al., 2013).

The exercise was found to be a more potent stimulus for bronchodilation than by inhaled $\beta 2$-agonists (Phillips et al., 1998). Considering the effects of exercise to enhance airway clearance and improve functional capacity in patients with bronchiectasis and chronic lung diseases, we were in favor of including aerobic exercise training for treatment program of our patient. This case report was the first report to demonstrate the effects of aerobic exercise training of a patient with Kartagener syndrome. Our patient exhibited increased exercise capacity and also showed decreased dyspnea and fatigue scores with exercise training, without presenting any sign of exacerbation.

The pulmonary function parameters of the patient after exercise training were similar to her baseline values. A 6-month super-
Table 3. Physical activity parameters before and after exercise training

\begin{tabular}{lcc}
\hline Physical activity parameter & Before & After \\
\hline Daily energy expenditure (kcal/day) & 1,774 & 1,798 \\
Daily physical activity duration ( $\geq 1.5 \mathrm{MET}$ ) & $11.63 \mathrm{hr}$ & $8.11 \mathrm{hr}$ \\
Lying down (hr/day) & $9.28 \mathrm{hr}$ & $9.38 \mathrm{hr}$ \\
Daily active energy expenditure ( $\geq 1.5 \mathrm{MET}$ ) (kcal/day) & $1,051 \mathrm{kcal}$ & $912 \mathrm{kcal}$ \\
Step counts (steps/day) & 5,015 & 6,212 \\
Sleep duration (hr/day) & $7.88 \mathrm{hr}$ & $7.06 \mathrm{hr}$ \\
MET & 1.7 & 1.6 \\
Distance (km/day) & 2.9 & 4.3 \\
Physical activity level index & 1.4 & 1.5 \\
Mean sedentary activity duration (<1.5 MET) & $12.06 \mathrm{hr}$ & $15.75 \mathrm{hr}$ \\
Light physical activity duration (1.5-3 MET) & $10.55 \mathrm{hr}$ & $6.56 \mathrm{hr}$ \\
Moderate physical activity duration (3-6 MET) & $1.25 \mathrm{hr}$ & $1.30 \mathrm{hr}$ \\
Vigorous physical activity duration (6-9 MET) & $7 \mathrm{~min}$ & $14 \mathrm{~min}$ \\
Very vigorous physical activity duration (>9 MET) & $1 \mathrm{~min}$ & $4 \mathrm{~min}$ \\
\hline
\end{tabular}

MET, metabolic equivalent.

vised training program was shown to improve lung function including $\mathrm{FEV}_{1}$ and aerobic performance in patients with cystic fibrosis underlining the importance of physical activity (Kriemler et al., 2013). It was reported that the benefits of regular care plus exercise training might be influenced by the type and duration of the training program in patients with cystic fibrosis (Radtke et al., 2017). We did not observe such difference in our results probably due to relatively shorter time, eight weeks, of aerobic exercise training program.

The ISWT distance increased $90 \mathrm{~m}$ after training compared with the distance before aerobic exercise training. The $47.5 \mathrm{~m}$ was identified as the minimum clinically significant improvement for the ISWT in patients with chronic obstructive pulmonary disease (Singh et al., 2008). In the same study, $78.7 \mathrm{~m}$ was determined a higher level of perceived improvement. Our patient's result was higher than these.

We evaluated the physical activity level of a patient with a Kartagener Syndrome before and after aerobic exercise training. There is no evidence of physical activity level in this disease other than we provided. According to our findings, our patient showed a sedentary lifestyle, and her results were similar before and after exercise training. However, our patient achieved the required physical activity level, at least $150 \mathrm{~min}$ of aerobic activity or at least 75 min of vigorous aerobic activity, or the equivalent combination of both activities per week, which defined by World Health Organization's (WHO) recommendations for maintenance of cardiovascular health (World Health Organization, 2010). We believe exercise training may have a favorable role to adopt a relatively more active lifestyle. 
Tudor-Locke and Bassett (2004) classified physical activity level $<5,000$ steps/day as a sedentary lifestyle index; 5,000-7,499 steps/ day as low active; 7,500-9,999 steps/day as somewhat active; and $>$ or $=10,000 \mathrm{steps} /$ day as active. The same study reported that 5,000-7,499 steps/day considered as low active which was inferred as typical of daily activity excluding sports or exercise (Tudor-Locke and Bassett, 2004). We can classify our patient as low active. The daily step count of our patient before training and after training was respectively 5,015 steps/day and 6,212 steps/day.

According to the findings, the aerobic exercise training program in addition to standard physiotherapy treatment for a patient with Kartagener syndrome was a success by improving exercise capacity, lowering perceived dyspnea and fatigue with exertion.

Respiratory muscle strength assessment and, if required, respiratory muscle strength training may be helpful for management of the disease. We were not able to provide this due to technical issues. However, respiratory training may have been confounding with the effects of individual aerobic exercise training. In this respect, evaluation and investigating the impact of respiratory training in this population may be considered.

This is the first case report of a Kartagener's syndrome patient who attended aerobic exercise training including the assessment of physical activity level. The functional capacity of patient increased after training. We recommend exercise training in patients with Kartagener syndrome to increase exercise capacity and relief the symptoms.

\section{CONFLICT OF INTEREST}

No potential conflict of interest relevant to this article was reported.

\section{REFERENCES}

Barbato A, Frischer T, Kuehni CE, Snijders D, Azevedo I, Baktai G, Bartoloni L, Eber E, Escribano A, Haarman E, Hesselmar B, Hogg C, Jorissen M, Lucas J, Nielsen KG, O'Callaghan C, Omran H, Pohunek P, Strippoli MP, Bush A. Primary ciliary dyskinesia: a consensus statement on diagnostic and treatment approaches in children. Eur Respir J 2009;34:1264-1276.

Cole PJ, LeMura LM, Klinger TA, Strohecker K, McConnell TR. Measuring energy expenditure in cardiac patients using the Body Media Armband versus indirect calorimetry. A validation study. J Sports Med Phys Fit- ness 2004:44:262-271.

Cox NS, Alison JA, Button BM, Wilson JW, Morton JM, Dowman LM, Holland AE. Validation of a multi-sensor armband during free-living activity in adults with cystic fibrosis. J Cyst Fibros 2014;13:347-350.

Hill K, Dolmage TE, Woon L, Goldstein R, Brooks D. Measurement properties of the SenseWear armband in adults with chronic obstructive pulmonary disease. Thorax 2010;65:486-491.

Kriemler S, Kieser S, Junge S, Ballmann M, Hebestreit A, Schindler C, Stüssi C, Hebestreit H. Effect of supervised training on FEV1 in cystic fibrosis: a randomised controlled trial. J Cyst Fibros 2013;12:714-720.

Leigh MW, Pittman JE, Carson JL, Ferkol TW, Dell SD, Davis SD, Knowles MR, Zariwala MA. Clinical and genetic aspects of primary ciliary dyskinesia/Kartagener syndrome. Genet Med 2009;11:473-487.

Madsen A, Green K, Buchvald F, Hanel B, Nielsen KG. Aerobic fitness in children and young adults with primary ciliary dyskinesia. PLoS One 2013;8:e71409

Mandal P, Sidhu MK, Kope L, Pollock W, Stevenson LM, Pentland JL, Turnbull K, Mac Quarrie S, Hill AT. A pilot study of pulmonary rehabilitation and chest physiotherapy versus chest physiotherapy alone in bronchiectasis. Respir Med 2012;106:1647-1654.

Miller MR, Hankinson J, Brusasco V, Burgos F, Casaburi R, Coates A, Crapo R, Enright P, van der Grinten CP, Gustafsson P, Jensen R, Johnson DC, MacIntyre N, McKay R, Navajas D, Pedersen OF, Pellegrino R, Viegi G, Wanger J; ATS/ERS Task Force. Standardisation of spirometry. Eur Respir J 2005;26:319-338.

Phillips GE, Thomas S, Heather S, Bush A. Airway response of children with primary ciliary dyskinesia to exercise and beta2-agonist challenge. Eur Respir J 1998;11:1389-1391.

Pifferi M, Di Cicco M, Piras M, Cangiotti AM, Saggese G. Up to date on primary ciliary dyskinesia in children. Early Hum Dev 2013;89 Suppl 3:S45-48

Probst VS, Hernandes NA, Teixeira DC, Felcar JM, Mesquita RB, Gonçalves CG, Hayashi D, Singh S, Pitta F. Reference values for the incremental shuttle walking test. Respir Med 2012;106:243-248.

Radtke T, Nevitt SJ, Hebestreit H, Kriemler S. Physical exercise training for cystic fibrosis. Cochrane Database Syst Rev 2017;11:CD002768.

Singh SJ, Jones PW, Evans R, Morgan MD. Minimum clinically important improvement for the incremental shuttle walking test. Thorax 2008;63: 775-777.

Tudor-Locke C, Bassett DR Jr. How many steps/day are enough? Preliminary pedometer indices for public health. Sports Med 2004;34:1-8.

World Health Organization. Global recommendations on physical activity for health. Geneva (Switzerland): World Health Organization; 2010. 